ISSN: 2146-3042

DOI:

\title{
Real-Time Blockchain Accounting System As A New Paradigm*
}

\author{
Betül Şeyma ALKAN**
}

\begin{abstract}
The aim of this study is to evaluate the advantages by examining the effect decentralized blockchain applications on accounting information systems. The blockchain as an Distributed Ledger Technology (DLT) offers new possibilities to recording and backing up sensitive and confidential data of accounting information systems. The blockchain is designed in a structure that allows transactions to be monitored and controlled in real-time. By this way, the question of how to operate the real-time accounting system, as a new paradigm with blockchain technology, and how to apply in the field of taxation have emerged simultaneously. To achieve the aim of the study, a descriptive approach was adopted to explore the basics of blockchain technology and the most important accounting practices (such as accounting entries, taxation). For that purpose, the relevant literature on blockchain accounting system were reviewed and the blockchain reports of the big four companies were examined. As a result, the potential advantages of real-time blockchain accounting system were categorized according to four focus points: transparency and trust; disintermediation;smart contracts; continuous audit.
\end{abstract}

Keywords: Blockchain, Accounting Information System, Smart Contracts, Transparency.

JEL Classification: M40, O30,O31.

\section{Yeni Bir Paradigma Olarak Gerçek Zamanlı Blok Zinciri Muhasebe Sistemi ÖZET}

Bu çalışmanın amacı, merkezi olmayan blok zinciri uygulamalarının muhasebe bilgi sistemleri üzerindeki etkisini inceleyerek avantajlarını değerlendirmektir. Dağıtık Defter Teknolojisi (DLT) olarak blok zinciri, muhasebe bilgi sistemlerinin hassas ve gizli verilerini kaydetmek ve yedeklemek için yeni olanaklar sunar. Blok zinciri, işlemlerin gerçek zamanlı olarak izlenmesine ve kontrol edilmesine izin veren bir yapıda tasarlanmıştır. Böylelikle blok zinciri teknolojisinin sunduğu altyapı itibariyle gerçek zamanl muhasebe sisteminin nasıl işletileceği ve vergilendirme alanında nasıl uygulanacağ soruları eş zamanlı olarak ortaya çıkmıştır. Çalışmanın amaçlarına ulaşmak için, blok zinciri teknolojisinin temellerini ve en önemli muhasebe uygulamalarını (muhasebe kayıtları, vergilendirme gibi) keşfetmek için tanımlayıcı bir yaklaşım benimsenmiştir. Bu amaçla, blok zinciri muhasebe sistemine ilişkin ilgili literatür ve büyük dörtlü şirketlerin blok zinciri raporları incelenmiştir. Sonuç olarak, gerçek zamanlı blok zinciri muhasebe sisteminin potensiyelavantajları; şeffaflı ve güven; aracısızlaşma; akıllı sözleşmeler ve sürekli denetim olmak üzere dört odak noktasına göre kategorize edilmiştir.

Anahtar Kelimeler: Blok Zinciri, Muhasebe Bilgi Sistemi, Akıllı Sözleşmeler, Şeffaflık.

Jel Sinıflandırması: M40, O30,031.

\footnotetext{
* Bu makale, 23-25 Nisan 2021 tarihleri arasında gerçekleştirilen VI. Uluslararası Muhasebe ve Finans Sempozyumunda bildiri olarak sunulmuştur.

Makale Gönderim Tarihi: 09.06.2021, Makale Kabul Tarihi: 01.07.2021, Makale Türü: Kuramsal

** Assist. Prof. Dr., İzmir Bakırçay University, betul.alkan@bakircay.edu.tr, ORCID: 0000-0002-4942-669X
} 


\section{INTRODUCTION}

The blockchain is a set of cryptographically linked datablocks that allow management of the entire history of transactions performed through a decentralized ledger. Different peerto-peer (P2P) nodes validate transactions cryptographically and do not need a central authority to verify information. Since blockchain technology is structured on a peer-to-peer network that is not dependent on a central authority, hash value that is a cryptographic method, is used as the trust mechanism for recording transactions. The transaction information are entered in a block with hash value of information and the hash value for the previous block the chain. A decentralized operating system called "proof of work" is used to protect this chain. One of the key features of a Blockchain based Accounting Information System (AIS) is that the organization of information in a distributed, decentralized and shared chain of blocks. Thus, it creates a database managed by multiple users distributed in the P2P network which is why it is defined as a Distributed Ledger Technology (DLT) (Wu et.al., 2019:100093; Weigand et.al., 2019:344; Kokina et.al., 2017:94; Dai and Vasarhelyi, 2017:8).

In DLT, transaction are entered and stored in a distributed ledger that is accessible to all interested parties. In this case, regulators, auditors, and clients will each have an identical copy of the ledger (Martin, 2018:1). One of the strongest aspects of blockchain technology is transparency. At this context, it is important to protect the privacy of the distributed information.

All users on the network are responsible for verifying that the data added to the blockchain is genuine. This stage is done using different key systems (private and public key) that allow users to check the accuracy of data as well as confirm who it came from. The transaction is sent to the public address of the recipient (public key) and digitally signed using the sender's private key.

Another key feature of blockchain technology is immutability. The transaction are added in blocks chained to each other. Each block needs to be verified by different nodes before it can be included in the chain. Operating scheme in which block copies are kept at different independent and decentralized points makes verified and transactions added to the chain unilaterally unchangeable (Tan and Low, 2019:315; Stein, 2018:79; O 'Leary, 2018:7).

Accountants, managers, business partners and investors as users of accounting information in the real-time blockchain accounting system can actively collaborate to validate transactions. It can also provide reliable evidence for cross validation. The combination of these components creates a real-time, verifiable and transparent accounting ecosystem (Dai and Vasarhelyi, 2017:9).

Thus, the blockchain will increase auditability. By securing the data recorded in blocks, the verification of documents during the audit process will be faciliate. It becomes possible to track and control the assets and liabilities recorded in the blockchain, whose location and status are constantly updated. This will particularly pave the way for remote realtime stock review. Moreover, even audit trails can be documented on the blockchain to facilitate future monitoring and inspection (Mainelli and Smith, 2015:29-30). 
The aim of this study is to clarify the developments in various usage areas of blockchain technology and to determine the possibility of using this technology in accounting transactions. It also aims to demonstrate how to use real-time blockchain accounting information systems and identify the most important potential impacts of its technical use in accounting information systems.

The importance of the research stems from the novelty of the subject and the lack of accounting research in the field, and also the need for research on how to benefit from various recent developments in the information technology environment in accounting information systems studies.

The academic literature on the basic function, application and technical features of the system regarding the intersections between blockchain technology and accounting is not sufficient. After a comprehensive review of the present literature, operating of blockchain technology and its effects on accounting information systems and the concept of real-time accounting system as a new paradigm were evaluated. Also, the research reports of Deloitte, Ernst \& Young, KPMG and PwC including the perspectives, insights and analysis related to blockchain are reviewed in detail.

In the first part of the study, the operational fit of blockchain technology in accounting information systems will be discussed. We consider the triple-entry accounting system and its operation, which includes blockchain technology versus traditional accounting information systems. Then, the use of blockchain technology in accounting information systems will be examined and the advantages of the system are discussed in terms of four focus points.

\section{BLOCKCHAIN TECHNOLOGY}

Blockchain technology is a technology that was originally developed to support Bitcoin (cryptocurrency) and enables transactions to be carried out without any third party (Biswas and Muthukkumarasamy, 2016:1392). In traditional transactions, money transfers are managed through a third party bank or institution. Therefore, all transactions are controlled by these centrally located institutions (Huuma et al., 2016:1-2). However, blockchain technology removes the mechanism of trust in the central authority and imposes trust on the decentralized network. Hence, commercial and legal transactions are carried out in a distributed, reliable and accountable environment without using a central server on the blockchain. A blockchain database consists of nodes (computers). Thus, the record of transactions is kept collectively by a network of computers/nodes. Brown (2016) stated that the unreliable nature of the network requires a verification process for participating nodes to reach consensus on shared records.

Nodes are responsible for adding new blocks to the blockchain. A new block can be added only after all nodes in the system reach a consensus. In other words, all participants agree that this block is legitimate and contains only valid transactions. The new block is shared among all nodes in the system; it is monitored by every node but cannot be directly changed by any (Inghirami, 2019:4).

Data (transactions) in the blockchain are divided into blocks. "Blocks" are made up of pieces of digital information. Each block is linked to the previous one. The first block is 
called the genesis block (Zheng et al., 2017:558). Reiff (2020) also stated that blocks are structures where all kinds of data containing values are stored. Block parts have three parts.

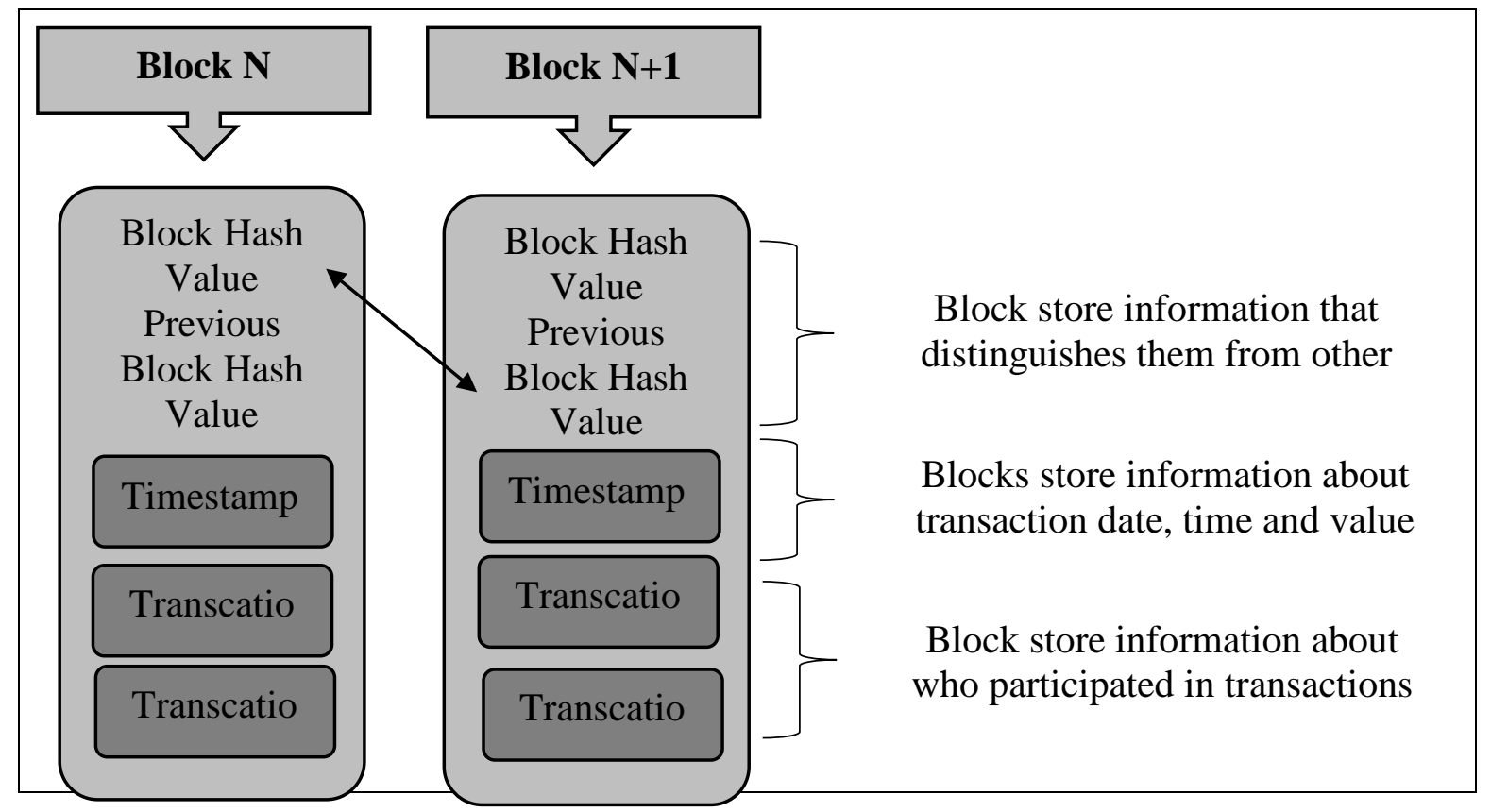

Figure 1. Block Information Containing Records of Transactions Source:Figure created by author

Blockchain, the most common application of DLT, uses cryptographic tools in addition to the distributed consensus process to create a significant innovation in traditional bookkeeping. DLT is when two companies that are parties to a transaction on a distributed network use the same ledger and the computers (nodes) in the system apply verification techniques to provide a consensus about the transaction (Liu and $\mathrm{Xu}, 2017: 1853$ ).

The main feature of blockchain is that transaction data is stored in blocks with value containing cryptographic references to previous blocks. To protect the blockchain, a decentralized system of work called "proof of work" is used.In this context, the possibility of manipulation is quite low. Nodes are responsible for completing the "proof of work". The first "miner" who manages to decrypt the "proof of work", verify the transaction and create a new block that must be verified by all nodes in the network is rewarded with a fee.In this way, the transaction can be verified through the network of nodes without the need for a central authority and provides all the information through a public ledger. When a change is made in any block, it must be changed in all blocks in the chain (Durbilmez and Turkmen, 2018:32). However, this is almost impossible. Because blocks are available to all participants in the blocks with the distributed ledger technique. The information contained in the account ledgers of all users must also be corrected. As Tysiac (2017) stated, this infrastructure is behind the factors that make blockchain reliable.The blockchain ledger based on DLT facilitates purchasing processes, ensuring that transactions are securely recorded in a way that can lead to incomparable transparency and increased operational efficiency.

There have been significant initiatives by big four auditing companies towards the adoption of blockchain technology (Karajovic et al.,2019:6). It is expressed by Patrizio (2018) 
and Inghirami (2019) that auditing companies have started to offer solutions that include blockchain technology, based on the "Blockchain as a Service (BaaS)" Approach. A blockchain platform that generates digital assets (Vulcan) has been developed by PwC Australia. Thus, an infrastructure that combines financial and commercial services has been designed. Powered by blockchain technology, digital currencies are intended to fundamentally change the way consumers, banks and businesses interact. Deloitte started work on its own blockchain system (Rubix) in 2014 to simplify and speed up the auditing process using blockchain. It aims to seek to improve supply-chain management and solve issues related to digital identity and commerce, international transactions and banking, and the management of loyalty and rewards programs. Through a collaboration with Microsoft, KPMG has launched the "Digital Ledger Service" to customers about how blockchain can help increase the speed and security of transactions, reduce costs and digitize administrative processes. EY has launched an Ethereum-based procurement solution (OpsChain Network Procurement) for businesses. The solution, which allows the execution of procurement activities on the blockchain, is designed to transform purchase agreements into digital smart contracts (Fullana and Ruiz, 2019:18).

Based on the Blockchain as a Service (BaaS) approach, these solutions focus on business value and productivity growth by eliminating third parties in real-time accounting system, asset tracking, inventory management, supply chain management. The main focus of the real-time blockchain accounting system (RBAS) is to ensure that the ledger provides transparent and reliable information on the blockchain platform involving multi-party stakeholders (organizations, departments, individuals, etc.).

\section{REAL-TIME BLOCKCHAIN ACCOUNTING SYSTEM (RBAS)}

Information systems are accepted as the basic method in the process of redesigning the business. Most businesses use information technologies to redefine business processes to gain competitive advantage (Phan, 2003:582). The accounting information system allows information users to obtain information whenever and wherever they want, and enables the systematic circulation of financial information within the enterprise. The use of blockchain technology in accounting information systems has come to the fore as a technological solution. It presents important changes in terms of accounting theory, and as the use of digital currencies in terms of businesses becomes widespread, its effects in terms of reporting emerge. Blockchain technology has the potential to change the double-entry accounting system.

The blockchain distributed ledger structure, whose transactions cannot be deleted or changed, is defined as a digital ledger for accounting, which is basically a recording and reporting system. The parties to the commercial transactions record the transactions in their own ledgers by using the double-entry system. On the basis of blockchain technology, instead of making separate accounting entries in each enterprise based on documents, a registration system can be created that allows transactions to be recorded directly in a common ledger with the participation and approval of all parties. After the transaction registry is completed, it will be almost impossible to hide and destroy transactions, since it is cryptographically signed and distributed to all nodes (Doğan and Ertugay, 2019:1664). Therefore, transactions between parties in the blockchain are recorded and stored in the system in real-time and monitored instantly. "Real-time Blockchain Accounting System" (RBAS) is defined as a 
softwaresolution that enables the exchange of monetary values between two or more parties, records this exchange transaction, reliably stores it, and enables the preparation of financial statements when needed (Potekhina and Rumkin, 2017:12).

There are two parties involved in a typical business transaction: the party supplying the goods or services and the party demanding the goods or services. While one of the parties delivers the goods or provides the service, the other party pays or borrows for the relevant goods or services. Both parties record the relevant transaction separately in their own accounting systems. In the blockchain technology-based accounting system, the distributed ledger, which verifies the records in real time, participates in the registration process as a third party. The real-time blockchain accounting system proposes a triple-entry accounting system.Therefore, the blockchain distributed ledger is a third-party inclusion on the traditionally presented double-entry accounting (Dai and Vasarhelyi, 2017:11).

In the blockchain-based system, there are three entries of the accounting transaction: the debit side, the credit side, and the cryptographic signature of the transaction. These three entries also form three parties, the buyer, the seller, and the blockchain (Brandon, 2016:39).In other words, after the records are completed, they are signed encrypted and distributed to all nodes (transaction parties for acccounting). Therefore, this distributed ledger is the third party of the triple-entry accounting system (Hambiralovic and Karlsson, 2018:20). The use of blockchain technology to be a third party in the accounting system,provides a transparent, self-verifying accounting information system that includes cryptographic encryption, and it provides reliable information sharing for information users and continuous and real-time reporting for partners (Dai and Vasarhelyi, 2017:10).

In the distributed database system, each record carries a timestamp. In this context,real-time information needs of information users will be met with the development of accounting information systems that record verified transactions in secure ledgers on the basis of blockchain technology (Dai and Vasarhelyi, 2017:9). For this reason, predetermined accounting policies (such as stock valuation method, depreciation method) in accounting software or ERP systems are integrated into the blockchain database and are considered as a new database with the potential to be used with the existing accounting information system. Contrary to an ERP, processes that are organized in a centralized infrastructure, blockchain distributes the power of transaction verification, storage, and organization to a group of nodes/computers (Dai and Vasarhelyi, 2017:8).

\subsection{Triple-Entry Accounting System(TEA)}

Essentially, the triple-entry accounting system was first described by Grigg in 2005 as a system in which two parties (buyer or seller) transact and a third party approves. Today, it has found use with blockchain technology.This system is the system that provides transactions to be recordeddirectly in a common registry with the participation and approval of all transaction parties

The triple-entry accounting system proposed by Grigg is a distributed ledger system based on a three-way consensus mechanism. It relies on three-sided signed receipts to reach an agreement on registration (Odom, 2015:2). The transaction recording process, in which the parties are simultaneously involved, first begins with sending request to the network. The 
transaction request is sent to the system database to obtain the signatures of the parties. Before the transaction is committed to the database, the system checks and confirms the validity of the signatures. Thus, this mechanism creates a three-sided signed receipt that cannot be manipulated or deleted by the parties and where the data will be kept in one block. In the other words, the TEA system has a shared transaction block that keeps a single entry of the transaction (Ibañez et al. 2020: 6). The TEA system facilitates financial reporting, tax planning and auditing with sequential storage and classification of transactions (Ibañez et al. 2020:16).

The TEA system maintains a distributed ledger record of transactions between two or more parties with an offer-acceptance-verification structure. It is based on the principle of immutability of transactions. Hence the three-way consensus through digitally signed receipts suggested by Grigg (2005) ensures immutability. The manipulation and low level of trust of double-entry systems have made the immutability of the shared ledger of real-time transactions a fundamental requirement. The reliability of the TEA system on the basis of the blockchain is ensured by the digital verification feature. The TEA system acts as an archive that records transactions common to two or more parties. The transaction block in the system can be public or private.
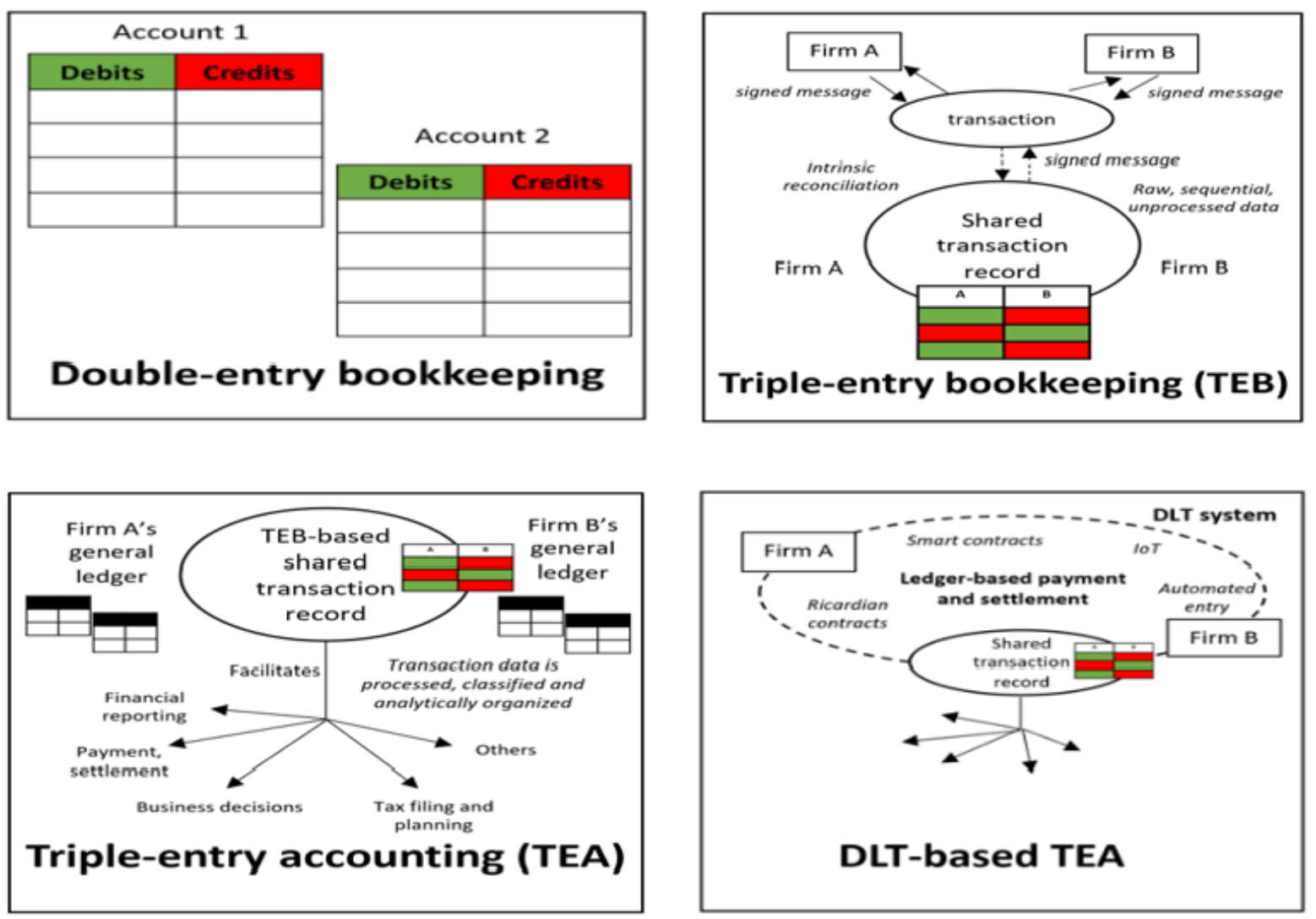

Figure 2. DLT-based TEA Systems 
The TEA system has address A, address $B$, and a third address, which is the verification receipt.The third public ledger allows both parties to reconcile their ledgers and reach consensus (Faccia and Mosteanu, 2019:111). The private TEA system can be encrypted, allowing only users with access rights to view transactions. Making access optional for each transaction according to the preference of the legal entity will increase the attractiveness of the TEA system (Pacio, 2019:3). Thus, thanks to the public blockchain technology, it is possible to enter transaction information into blocks, instead of the document-based book-keeping technique in the accounting units of enterprises. All information is monitored in real-time by all users registered in the system, with the distribution and approval of the transaction by recording in the block due to the distributed ledger structure of the blockchain. The distribution and approval of the transaction means that the accounting transaction cannot be fraudulent (Deloitte, 2016:3). In this way, the information user in the blockchain network will not have to wait for the interim financial reports according to quarterly time periods or the year-end financial reports. Information users will be able to trace all transactions in real-time.

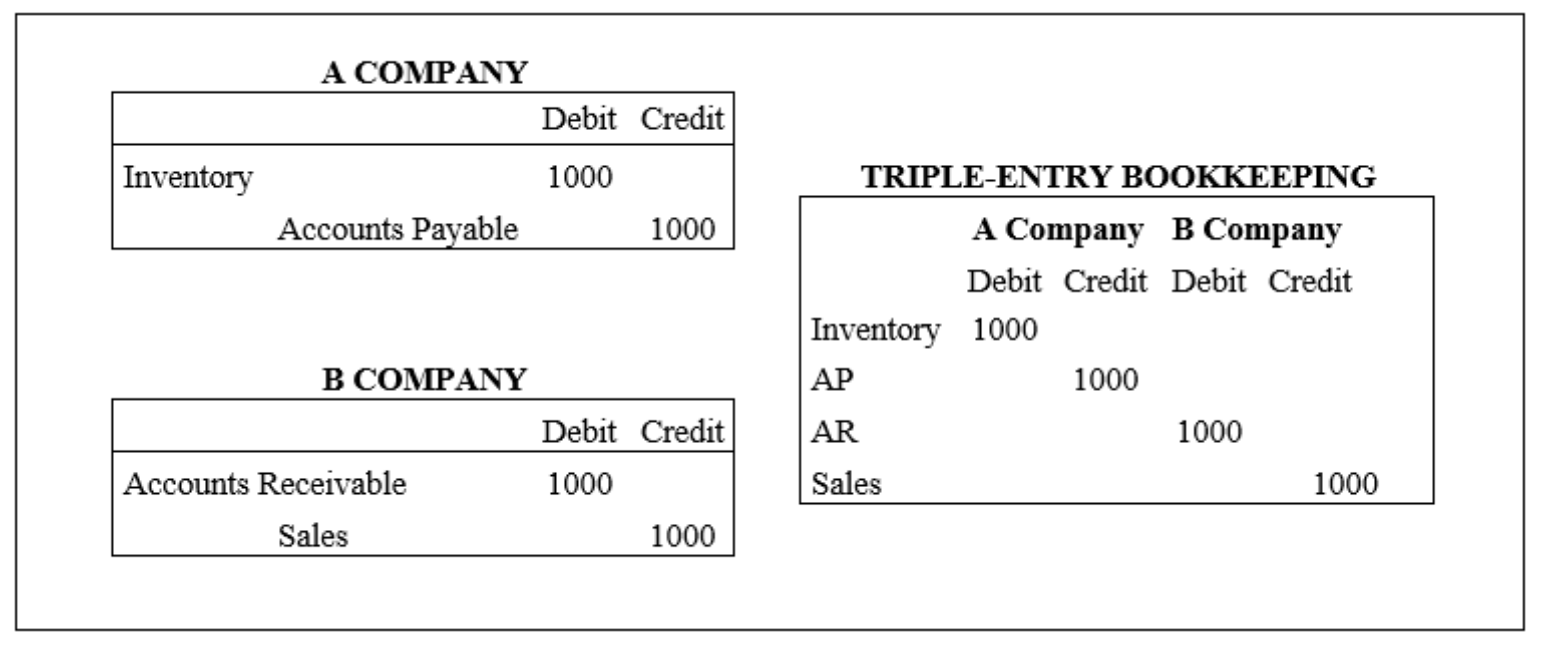

Figure 3.Triple-Entry Bookkeeping Sample

Source: Nordgren et.al., 2019:49

Figure 3 represents a triple-entry bookkeeping technique in a blockchain-based accounting information system. In the blockchain-based system, the enterprise records the internal and external activity flow in the common ledger and adds it to the chain. Thus, accounts can be tracked in the common ledger for different users. At the same time, the equality of assets and liabilities is achieved instantly (Dai and Vasarhelyi, 2017:11).

\subsection{Taxation System}

Although payroll systems in most of the developed economies have been equipped with an electronic infrastructure, the collection of taxes on wages with decentralized blockchain technology based on a distributed ledger system will both strengthen tax security for employers and workers and accelerate tax collection for governments (Johnston and Lewis, 2017:17). 
In the report "Blockchain technology and its potential on taxes" published in 2017, Deloitte emphasized that blockchain technology can have great effects for tax authorities, especially in the prevention of fraud. On the platform, it is stated that Value Added Tax (VAT) is separated from the transaction and transferred directly to the relevant tax authority, and the rest will be transferred to the relevant customer account (Deloitte, 2017:13). One of the most important problems in taxation is trust. In the proposed system, taxes can be downloaded and reported in real time using smart contracts for payments.

In the system, where VAT collection is made with blockchain technology through distributed entry, there will be smart contracts that automatically separate VAT from the purchase price and scan quick response codes (two-dimensional barcodes) on products.Thus, the tax liability will be separated from the price and sent directly to the treasury, resulting in significant reductions in transaction costs.In addition, thanks to smart contracts, VAT refunds will be realized quickly (WU/New Economy Taxation Team, 2017:8).

With the use of blockchain technology in tax systems, the current administrative burdens of businesses will be significantly reduced, time will be saved and costs will be reduced. At the same time, the details of the operational costs will be open to scrutiny simultaneously. Money transfers between businesses and public authoritieswill be ensured quickly. All transactions will be carried out in real time, fraudulent activities on transactions made through smart contracts will be significantly prevented and transparency will be ensured (Frankowski et al., 2017:13). Because transactions in the distributed entry system can be monitored in real time by tax offices and cannot be changed (Johnston and Lewis, 2017:16). In this context, it is clear that a blockchain-based taxation, which is seen as a positive way to prevent smuggling in the field of VAT, will provide transparency, high tax compliance and low cost to the economy.

\section{POTENTIAL IMPACT OF BLOCKCAHIN ON AIS}

Blockchain technology enables new business models, innovative organizational forms, or new business and production processes where "access" over ownership and "share" over ownership, and real-time accounting systems.In this context, blockchain technology offers advantages to practitioners and information users at various points.

Book-keeping with blockchain technologyprovides important advantages such as operational simplification, minimization of fraud and corruption risks in terms of accounting transactions, especially since a block added to the chain cannot be changed unilaterally without the consent of all parties in the transaction. Due to the fact that the relevant transactions are open to the supervision of all parties authorized inside and outside the organization, the efficiency and productivity of auditing will increase and operational simplification will be possible in auditing (CAA, 2017:22).

According to literature49is related to the use of blockchain technology in accounting, the potential advantages of real-time blockchain accounting system were categorized according to four focus points: transparency and trust; disintermediation; smart contracts; continuous audit. 


\subsection{Transparency and Trust}

There are two aspects to the use of blockchain technology in accounting. First of all, accounting transactions will be shared transparently through this technology, on the other hand, documents or document details of each transaction (invoice details, etc.) will be displayed and the accounting policies and methods used by the enterprise will be uploaded to the system. Thus, transaction assurance flow will be provided. In an accounting system based on blockchain technology, all monetary transactions of the business are recorded on the blockchain with the timestamp for each transaction. In this way, all accounting entries can be monitored simultaneously by all authorized parties of the business and all parties can see the real-time financial statements of the business. In this context, blockchain technology will enable to improve information quality and increase transparency by providing accounting transactions to parties in a more reliable and real-time manner (Byström, 2016: 4).

Blockchain system will improve the quality of accounting systems in terms of auditability and interoperability, as well as security, transparency and immutability in accounting entries (Piazza, 2017:296; Weigand et al., 2019:3). It will directly affect the governance and transparency for all company stakeholders to the extent that they can provide instant and accurate access to all data about the company. These features make a significant change in the company's risk assessment (Byström, 2019:44).

Blockchain, in essence, are public structures that fulfill the necessary conditions. In some applications, access to the blockchain can be bound to permission. The permission to participate in the blockchain network is divided into public blockchain and private blockchain according to the structure of the blockchain (Usta and Doğantekin, 2018: 32). The ability of private blockchain users to join the database is dependent on a specific invitation. In this context, some secret protocols can be provided. If businesses want to use such blockchains based on speed and privacy in terms of data processing and reporting, private blockchain will be more preferable (Jenner, 2017:1088). Yermack (2017) focuses on the possibility of providing differentiated (public or private) access to different parties and stakeholders, which will increase transparency and trust.

According to Bonsón and Beznárová (2019), there is a distinction between private and public blockchain, supported by a suitable architecture and improvements in cybersecurity. It will increase not only the quality of information, but also relevance, faithful representation, timeliness, comparability, verifiability, and the cost-benefit principle of accounting information. Therefore, it indicates that the accounting information system as a whole has been improved.

\subsection{Disintermediation}

Due to distributed ledger structure, the blockchainrecords the transactions of all participants on a single ledger and enables this service to be realized without centralized transaction processes. Therefore, even if the user is offline, without any time constraints, copies of the transactions can be accessed through the blockchain ledger.Since each blockchain stores copies of previous transactions within the chain, it is also possible to access each one retrospectively (Deloitte, 2017:4). 
In the blockchain system which provides disintermediation, all transactions must be approved and recorded by the transaction parties when adding them to the network or requesting changes. All parties in the system approve the validity of the change process, and the transaction only takes place in this way (Mansfield-Devine, 2017:17). In this context, the blockchain is based on the consensus of the transaction parties. Consensus is a method for verifying the chronological order in which requests, transactions, and information are executed, modified, or created. Correct ordering of transaction flows is important because it establishes ownership as well as rights and obligations. In a blockchain network, since there is no central authority that determines the order of transactions, approves transactions, and sets the rules for how nodes interact with each other, many validators implement peer-to-peer consensus protocols and all nodes'access to information is limited by the permission level. Therefore, the entries are transparent and monitorable (Aste, Tasca, Mateo, 2017:18). It functions as a shared, abuse-proof, shared ledger where entries are irretrievable through community consensus. It creates trust in the system by eliminating the need for compromise (Aste, Tasca, Mateo, 2017:18). However, in a system without a control mechanism, the accessibility of data for each user can be a concern for businesses. As a solution to this, the system offers public and private blockchain network alternatives. In the public blockchain, all users have access to transactions and data within the chain. In private blockchain, permission is required for participation in the network. Thanks to the permissioned blockchain technology, a shared ledger system operates within a network established by the relevant consortium (Deloitte, 2017: 5).

\subsection{Smart Contracts}

Blockchain systems allow the execution of programs that can perform accounting functions. The most important type of program used in blockchains is the smart contract. It is a set of rules that ensure the execution of contract conditions through computers. Smart contracts are software that run when certain conditions are met. After the contract parties agree on the subject of the contract, they are signed by the parties and added to the blockchain as a new block. When the contract conditions are fulfilled, the rules defined in the contract are executed. Therefore, smart contract implementation is based on the fact that any contract terms are converted into computer codes and stored in the blockchain and continued until the parties cancel or the contract terms are completed. In the current system, a central registry and distribution institution is needed to carry out a transaction between banks, and transaction times are prolonged as transactions are carried out through this center (Brennan and Lunn, 2016:9). Also, smart contracts are defined by Coyne McMickle (2017), Ølnes et al., (2017), Rozario and Vasarhelyi (2018) as digital programs that automate tasks related to contract execution, documentation or control, minimizing the need for trusted intermediaries. Therefore, smart contracts allow a series of tasks to be automated, reducing time, cost, and operational errors by eliminating the usually manual processes.

ACCA (2017) emphasizes that in terms of accounting applications, by applying smart contracts, invoice preparation operations will be transferred to computers with blockchain technology. For example, the computer will first check the blockchain to confirm that the goods are in stock and that the necessary resources are available to make the payment and an invoice will be paid automatically. Other interesting point highlighted by Rîndaşu (2019) about smart contracts is their potential to streamline accounting processes and thus provide an improvement in performance reporting costs. Weigan et al. (2019) emphasizes that the need 
for less coordination between units and greater privacy in transactions are the most important benefits of this technology.

Smart contracts have been developed to replace operational or administrative functions in internal and external reporting, and produce data that will reflect real results on time for performance targets and budgets (Wunsche, 2016:17-18). According to Dai and Vasarhelyi (2017) and Rozario and Vasarhelyi (2018), smart contract automates the transaction reconciliation procedure, increases transparency by issuing real-time reports.As stated by Kokina et al., (2017), decision-making processes are managed without intermediaries through smart contracts, under a predefined set of rules.It also facilitates audit processes and also reduces the risk specific to the human factor. However, there will always be the experience of the human factor and the functions that need to be evaluated. Therefore, the role of the auditor cannot be ignored (Rozario and Vasarhelyi, 2018:4).

\subsection{Continuous Audit}

Traditional audit services operate in a labor-intensive process. For the auditor, the preliminary preparation process brings together time, efficiency and cost issues (Schmitz and Leoni, 2019:336). Thanks to blockchain technology, it is possible to getcoded to auditable data that is verified, timestamped and immutable. Rules can be coded within the system, which allows automatic review through audit software. Therefore, the important effect of Blockchain technology on audit processes is to reduce time and cost (Potekhina and Riumkin, 2017:14).

In the blockchain network, transactions are approved by parties, submitted to the approval of the parties in case of any change, and provide a transaction trace reflecting the change to the books (Kokina et al., 2017: 96). Thanks to instant confirmation of transactions, blockchain technology provides real-time audit evidence (Schmitz and Leoni, 2019:336). Due to real-time audit, the authenticity of all transactions in the accounting information system and the accuracy of the amounts will be time-stamped, so the auditor spends a significant part of his/her time on performing other important stages of the audit instead of checking the reality or accuracy of these transactions (Potekhina and Riumkin, 2017:14-15). Thus, real-time audit will ensure continuous audit, thanks to time-stamped instant transactions. Thanks to continuous auditing, the auditor will be able to perform the audit activity more effectively. By obtaining objective data, high audit evidence will be provided and audit reliability will increase. In this way, audit risk will be minimized. It will be possible to detect or prevent fraudulent financial reporting with blockchain technology (Abreu et al., 2018: 4). However, in order to carry out continuous auditing activities in an enterprise that will have a blockchainbased accounting information system, all transactions must be recorded in this database. Only at this stage, the use of private (permissioned) blockchains prevents continuous audit activity (Schmitz and Leoni, 2019:336). In order for this system to function properly, the auditor must have an entry of all transactions updated in real-time (Rooney et al., 2017:43).

Finally, continuous auditing will reduce the incentives for customers to make false statements, which reduces the gap between the expectations of auditors, financial report users and regulators, increases the effectiveness of auditing. In this context, four big audit firms (PwC, Ernst \& Young, Deloitte and KPMG) are the first providers of blockchain technology by arranging and developing their audit applications according to this technology, in order to 
take advantage of the opportunities provided by blockchain technology and to gain an important field of activity in the market in the future. They continue to work to maintain their current position in the market today (Potekhina and Riumkin, 2017:14).

\section{DISCUSSION AND CONCLUSION}

Today, blockchain technology is described as a disruptive technology. Behind this definition lies that the technology operates on a peer-to-peer network that is not dependent on a central authority. Blockchain, which came to the fore with Bitcoin and is defined as a protocol-based technology in terms of the functioning of digital currencies, is integrated into business processes. As it is a new and developing area in business processes and it contains many innovations in the digital transformation process, it is not possible to fully reveal its effects. For this reason, many businesses have started to create their own prototype53technologies in order to identify the possibilities offered by blockchain technology and observe its possible effects (Deloitte, 2017: 1). Blockchain technology is designed in a structure that allows real-time monitoring and control of transactions within the ecosystem it provides, rather than a technological infrastructure. Accordingly, the idea of using blockchain infrastructure and databases in the accounting process is based on the fact that the blockchain is a ledger for bitcoin transactions by its53nature.Blockchain as a DLT ensures that transactions are securely recorded that can lead to unprecedented transparency and increased operational efficiency. In this context, blockchain technology will provide a revolutionary digital transformation for accounting systems. Schmitz and Leoni (2019) state that blockchain technology eliminates the need to enter and reconcile accounting information in multiple databases. As a result, it will save time and significantly reduce the risk of human error (Rìndaşu, 2019:145). Sheldon (2019) points out that the use of blockchain technology minimizes the risks associated with changing historical data and the need for data backup since batch processing.

In the literature, real-time accounting system concept related to blockchain-based accounting system; it is defined as a software solution that cryptographically protects transaction data in a peer-to-peer nodes, stores verified transactions in blocks and allows preparation of financial statements (Potekhina and Riumkin, 2017:12). In this context, realtime blockchain accounting system proposes a triple-entry accounting system and this system offers advantages in terms of four focus point: transparency and trust; disintermediation; smart contracts; continuous audit unlike the traditional accounting system.

Blockchain technology will be able to create new bases for accounting information systems by producing verified, real-time data sets. In addition, with a real-time accounting system, it will be possible to switch from periodic to continuous over time, that is, to real-time auditing. One of the key points in the evolution of blockchain-based accounting applications is the development of smart contracts. Using smart contracts, payments can be made automatically, transferring currencies or other assets on pre-agreed terms. Thus, with the taxation system based on the blockchain mechanism, the collection of taxes will be automated, transaction costs and especially value added tax smuggling activities will be reduced significantly.

These features makes this technology attractive to both auditors and all company stakeholders. Therefore, big four companies has started to join the consortium to develop 
applications within this technological framework. Providing a framework of new possibilities for accounting, distributed ledger systems offer a wide range of potential application opportunities, from external and internal transaction integrations, reconciliation, invoice automation, dispute resolution, anti-corruption and more.

As a result, in this study, blockchain technology,real-time accounting transactions expected to emerge with the use of blockchain technology and the use of this technology, the usability of the triple-entry accounting system, transparent and reliable information flow, continuous auditing, prevention of fraudulent financial reporting are mentioned. With the use of this technology, the development of new blockchain-based accounting information systems integrated with ERP systems can enable businesses to instantly transfer information to information users and ensure a high level of quality of information to be transferred. Thus, it can be ensured that the level of reasonable assurance given in the audit reports to be prepared as a result of the continuous audit activity for the auditors is much higher.

\section{REFERENCES}

Abreu, Pedro W. - Aparicio, Manuela - Costa, Carlos J. (2018), "Blockchain Technology In The Auditing Environment”, 13th Iberian Conference on Information Systems and Technologies (CISTI).

ACCA (2017),”Blockcahin: Accountancy's Transformer”, International edition of Accounting and Business magazine, https://www.accaglobal.com/my/en/member/member/accountingbusiness/2017/04/insi ghts/blockchain-17.html (Date Accessed: 27.02.2021)

Aste, Tomaso - Tasca, Paolo - Matteo, T Di (2017), "Blockchain Technologies: foreseeable impact on industry and society”, IEEE Computer, 50(9), pp. 18-28.

Brennan, Charles - Lunn, William (2016), “Blockchain: The Trust Disrupter”, Credit Suisse Securities (Europe) Ltd.: London, UK.

Biswas, Kamanashis - Muthukkumarasamy, Vallipuram (2016), "Securing Smart Cities Using Blockchain Technology”,IEEE 18th International Conference on High Performance Computing and Communications; IEEE 14th International Conference on Smart City; IEEE 2nd International Conference on Data Science and Systems, pp.1392-1393.

Brown, Richard G.(2016),“On Distributed Databases and Distributed Ledgers. Richard Gendal Brown: Thoughts on the Future of Finance” https:/gendal.me/2016/11/08/ondistributed-databases-and-distributed-ledgers/

Bonsón, Enrique - Bednárová, Michaela (2019), "Blockchain and its Implications for accounting and auditing”, Meditari Accountancy Research, (27)5, pp.725-740.

Brandon, Dan (2016), “The Blockchain: The Future of Business Information Systems?”, International Journal of the Academic Business World, 10(2), pp.33-40.

Byström, Hans (2016), "Blockchains, Real-Time Accounting and The Future of Credit Risk modeling”, Working Paper/Department of Economics, School of Economics and Management, Lund University.

Byström, Hans (2019), 'Blockchains, Real-time Accountingand the Future of Credit Risk Modeling', Ledger Journal, 4, pp.40-47. 
CAA (2017), “The Future of Blockchain: Applications and Implications of Distributed Ledger Technology”,https://www.charteredaccountantsanz.com//media/c1430d6febb3444192 436ffc8b685c7c.ashx

Coyne, Joshua G. - McMickle, Peter L. (2017), “Can Blockchains Serve an Accounting Purpose?', Journal of Emerging Technologies in Accounting, 14(2), pp.101-111.

Dai, Jun-Vasarhelyi, Miklos (2017), “Toward Blockchain-Based Accounting and Assurance”, Journal of Information Systems, 31(3), pp.5-21.

Deloitte (2016), “Blockchain Technology: A Game-Changer in Accounting?” https://www2.deloitte.com/content/dam/Deloitte/de/Documents/Innovation/Blockchai n_A\%20game-changer\%20in\%20accounting.pdf, (Date Accessed: 27.01.2021)

Deloitte Report (2017), “Blockchain Technology and Its Potential Impact on the Audit and its potential in taxes”, https://www2.deloitte.com/za/en/pages/audit/articles/impact-ofblockchain-in-accounting.html, (Date Accessed: 27.01.2021)

Digital Economy Taxation (2017), “Blockchain 101 for Governments”,WU Global Tax Policy Center of Vienna University of Business and Economics, Viyana, https://www.wu.ac.at/taxlaw/ institute/gtpc/events-and-activities/ (DateAccessed: 27.02.2021)

Doğan, Mustafa - Ertugay, Emrah (2019), "Blockchain and Applications in Accounting”, Third Sector Social Economic Review, 54(4), pp.1654-1670.

Durbilmez, Serap Erözel- Türkmen, Sibel Y1lmaz (2019), "Blockchain Teknolojisi ve Türkiye Finans Sektöründeki Durumu”, Finans Ekonomi ve Sosyal Araştırmalar Dergisi, 4 (1), pp.30-45.

Ernst \& Young, https://www.ey.com/en_gl/blockchain,(Date Accessed: 27.02.2021)

Faccia, Alessio - Mosteanu, Narcisa Rpxana (2019), “Accounting and Blockchain Technology: From Double-Entry to Triple-Entry”, The Business and Management Review, 10(2), pp.108-116.

Frankowski, Ernest-Baranski, Piotr - Bronowska,Marcjanna (2017),“Blockchain Technology and Its Potential in Taxes”, Deloitte. https://www2.deloitte.com/content/dam/Deloitte/pl/Documents/Reports/pl_Blockchain -technology-and-its-potential-in-taxes-2017-EN.PDF, (Date Accessed: 27.02.2021)

Fullana, Olga - Ruiz, Javier (2019), “Accounting Information Systems in The Blockchain Era”, https://ssrn.com/abstract=3517142

Grigg, Ian (2005), “Triple EntryAccounting”, Systemics Inc, Working Paper.

Hambiralovic, Mahir - Karlsson, Rasmus (2018), "Blockchain Accounting in a Triple-Entry System - Its Implications on the Firm and its”, http://lup.lub.lu.se/studentpapers/record/8953732

Huumo, Jesse Li - Ko, Deokyoon - Choi, Sujin - Park, Sooyong - Smolander, Kari (2016), "Where Is Current Research on Blockchain Technology? A Systematic Review", Plos One, 11(10), pp.1-27.

Ibañez, Juan Ignacio - Bayer, Chris N. - Tasca, Paolo - Xu, Jiahua (2020), “REA, Triple-entry 
Accounting and Blockchain: Converging Paths to Shared Ledger Systems.” Social Science Research Network (SSRN), http://dx.doi.org/10.2139/ssrn.3602207

Ibañez, Juan Ignacio - Bayer, Chris N. - Tasca, Paolo - Xu, Jiahua (2021), “Triple-entry Accounting, Blockchain and Next of Kin: Towards a Standardization of Ledger Terminology”,https://ssrn.com/abstract=3760220 or http://dx.doi.org/10.2139/ssrn.376 0220

Inghirami, Iacopo Ennio (2019), “Accounting Information Systems:The Scope of Blockchain Accounting”, Conference Paper, ITAISand MCIS 2019: 13th Mediterranean Conference on Information Systems and 16th Conference of the Italian Chapter of AIS

Johnston, Stephanie Soong - Lewis, Alexander (2017), "New Frontiers: Tax Agencies Explore Blockchain” Tax Notes International, 86(9), pp.16-19.

Jenner, Simon (2017), “Blockchain: The Digital Tax Function’s Leading-Edge Technology?”, Tax Notes International, 88(11), pp.1087-1089.

Karajovic, Maria -Kim, Henry M.- Laskowski, Marek (2019), “Thinking Outside the Block: Projected phases of blockchain integration in the accounting industry”, Australian Accounting Review, 29 (2), pp.319-330.

Kokina, Julia - Mancha, Ruben - Pachamanova, Dessislava (2017), “Blockchain: Emergent Industry Adoption and Implications for Accounting”, Journal of Emerging Technologies in Accounting, 14(2), pp.91-100.

KPMG,https://home.kpmg/xx/en/home/insights/2017/02/digital-ledger-services-at-kpmg-fs html, (Date Accessed: 27.02.2021)

Lu, Qinghua - Xu, Xiwei (2017), “Adaptable Blockchain-Based Systems: A Case Study for Product Traceability” IEEE Software, 34(6), pp.21-27.

Mainelli, Michael - Smith, Mike (2015), "Sharing Ledgers for Sharing Economies: An Exploration of Mutual Distributed Ledgers (Aka Blockchain Technology)”, Journal of Financial Perspectives, 33, 1, pp.47.

Mansfield-Devine, Steve (2017), "Beyond Bitcoin: Using Blockchain Technology to Provide Assurance in the Commercial World”, Computer Fraud \& Security, 5, pp.14-18.

Martin, Rich (2018), “How Blockchainwill Impact Accounting”, https://igniteoutsourcing.com/blockchain /blockchain-accounting-applications/, (Date Accessed: 27.02.2021.

Nordgren, Aino - Weckströn, Ellen - Martinkainen, Minna - Lehner, Othmar M. (2019),"Blockchain in the Fields of Finance and Accounting: A Disruptive Technology or an Overhyped Pehonmenon?”, ACRN Journal of Finance and Risk Perspectives 8, Special Issue Digital Accounting, pp. 47-58

Odom, Chris (2015), “Open-Transactions: Secure Contracts Between Untrusted Parties.” Open-Transactions White Paper. http://www.opentransactions.org/opentransactions.pdf (Date Accessed: 17.04.2021)

O'Leary, Daniel (2018), “Open Information Enterprise Transactions:Business Intelligence and Wash and Spoof Transactions in Blockchain and Social Commerce", Intelligent Systems in Accounting, Finance and Management, 25(3), pp.148-158. 
Ines, Svein - Ubacht, Jolien - Janssen, Marjin (2017), "Blockchain in government: Benefits and implications of distributed ledger technology for information sharing”, Government Information Quarterly, 34(3), pp.355-364.

Pacio (2019), “Pacio White Paper”, https://pacio.io/docs/PacioWhitePaper.pdf

Patrizio, Andy (2018), “The Top 10 Blockchain as a Service Providers. Datamation, https://www. datamation. com/data-center/top-10-blockchain-as-a-service-providers. html

Phan, Dieu (2003), "E-business Development for Competitive Advantages: A Case study”, Information and Management, 40(6), pp.581-590.

Piazza, Fiammetta S. (2017), "Bitcoin and The Blockchain as Possible Corporate Governance tools: Strengths and weaknesses”, Bocconi Legal Papers, 9, pp.125-156.

Potekhina, Anastasiia - Riumkin, Ivan (2017),“Blockchain-A New Accounting Paradigm: Implications for Credit Risk Management”. http://www.divaportal.org/smash/record.jsf?pid=diva2\%3A1114333\&dswid=7579

(Date Accessed: 27.02.2021)

PriceWaterhouseCoopers, https://www.pwc.com/gx/en/industries/technology/blockchain.html (Date Accessed: 27.02.2021)

Reiff, Nathan (2020), “Blockchain Explained”, https:/www.investopedia.com/ terms/b/ blockchain.asp

Rîndaşu, Sinziana Maria (2019), “Blockchain in Accounting:Trick or Treat?”, Quality-Access to Success, 20(170), pp.143-147.

Rooney, Hugh - Aiken, Brian - Rooney, Megan (2017), "Is Internal Audit Ready for Blockchain?”, Technology Innovation Management Review, 7(10), pp.41-44.

Rozario, Andrea M. - Vasarhelyi, Miklos A. (2018), “Auditing with Smart Contracts”, International Journal of Digital Accounting Research, 18, pp.1-27.

Schmitz, Jana - Leoni, Giulia (2019), “Accounting and Auditing at the Time of Blockchain Technology: A Research Agenda”, Australian Accounting Review, 29(2), pp.331-342.

Sheldon, Mark D. (2019), “A Primer for Information Technology General Control Considerations on a Private and Permissioned Blockchain Audit”, Current Issues in Auditing, 23 (1), pp.A15 - A29.

Stein Smith, Sean (2018), "Implications of Next Step Blockchain Applications for Accounting and Legal Practitioners: A Case Study", Australasian Accounting, Business and Finance Journal, 12(4), pp.77-90.

Tan, Boon Seng - Low, Kin Yew (2019), "Blockchain as the Database Engine in the Accounting System”, Australian Accounting Review, 29(2), pp.312-318.

Tysiac, Ken (2017), “Blockchain Considerations for Management and Auditors”, Journal of Accountacy, https://www. journalofaccountancy.com/news/2017/dec/blockchain-formanagement-and-auditors-201717994.html

Weigand, Hans - Blums, Ivars - Kruijff, Joost De (2019), "Shared Ledger Accounting Implementing the Economic Exchange pattern”, Information Systems, pp.101437 
Wunsche, Alan (2016), “Technological Disruption of Capital Markets and Reporting?”, file://C:/Users/SONY2020/Downloads/G10157-RG-Technological-Disruption-ofCapital-Markets-Reporting-Introduction-to-Blockchain-October-2016\%20(1).pdf

Wu, Jiapeng - Xiong, Feng - Li, Cheng Li (2019), “Application of Internet of Things and Blockchain Technologies to Improve Accounting Information Quality”, IEEE Access, 7, pp.100090-100098.

Yermack, David (2017), “Corporate governance and blockchains”, Review of Finance, 21(1), pp.7-31.

Zheng, Zibin - Xie, Shaoan - Dai, Hong Ning - Chen, Xiangping - Wang, Huaimin (2018), "Blockchain challenges and opportunities: A survey", International Journal of Web and Grid Services, 14(4), pp.352-375. 